\title{
Effects of etanercept, a tumor necrosis factor receptor fusion protein, on primary cell cultures prepared from intact human intervertebral disc tissue
}

\author{
TEZCAN CALISKAN $^{1}$, DUYGU YASAR SIRIN ${ }^{2}$, NUMAN KARAARSLAN ${ }^{1}$, IBRAHIM YILMAZ ${ }^{3}$, \\ HANEFI OZBEK $^{3}$, YENER AKYUVA ${ }^{4}$, NECATI KAPLAN $^{5}$, YASIN EMRE KAYA ${ }^{6}$, \\ ABDULLAH TALHA SIMSEK ${ }^{1}$, ALIYE YILDIRIM GUZELANT ${ }^{7}$ and OZKAN ATES ${ }^{8}$ \\ ${ }^{1}$ Department of Neurosurgery, Namik Kemal University School of Medicine; \\ ${ }^{2}$ Department of Molecular Biology and Genetics, Faculty of Arts and Sciences, Namik Kemal University,
} \author{
Tekirdag 59100; ${ }^{3}$ Department of Medical Pharmacology, Istanbul Medipol University School of Medicine, Istanbul 34810; \\ ${ }^{4}$ Department of Neurosurgery, Gaziosmanpasa Taksim Training and Research Hospital, Istanbul 34433; \\ ${ }^{5}$ Department of Neurosurgery, Corlu Reyap Hospital, Istanbul Rumeli University, Tekirdag 59680; \\ ${ }^{6}$ Department of Orthopedic and Traumatology, Abant Izzet Basal University School of Medicine, Bolu 14000; \\ ${ }^{7}$ Department of Physical Medicine and Rehabilitation, Corlu Reyap Hospital, Istanbul Rumeli University, \\ Tekirdag 59680; ${ }^{8}$ Department of Neurosurgery, Esencan Hospital, Istanbul Esenyurt University, Istanbul 34570, Turkey
}

Received July 11,2018; Accepted February 6, 2019

DOI: $10.3892 /$ etm.2019.7559

\begin{abstract}
The aim of the present study was to investigate the effects of etanercept (ETA), a tumor necrosis factor (TNF) inhibitor, on human cell cultures prepared from intact intervertebral disc tissue. ETA is used as a treatment for cases of rheumatoid arthritis, psoriatic arthritis, axial spondyloarthritis and ankylosing spondylitis accompanied by moderate or severe joint pain. ETA was applied to primary cell cultures [annulus fibrosus and nucleus pulposus (NP) from intact intervertebral disc tissue]. Cell cultures without ETA treatment served as the control group. Morphological and quantitative molecular analyses of the two groups were performed. The number of viable cells and cell proliferation decreased in the ETA-treated cultures as compared with those in the control group. Furthermore, in
\end{abstract}

Correspondence to: Dr Numan Karaarslan, Department of Neurosurgery, Namik Kemal University School of Medicine, 1-14 Campus Street, Tekirdag 59100, Turkey

E-mail: numikara@yahoo.com

Abbreviations: AF, annulus fibrosus; CAT, catalase; CHAD, chondroadherin; COMP, cartilage oligo matrix protein; DMARDs, disease-modifying antirheumatic drugs; DRG, dorsal root ganglion; ETA, etanercept; IL, interleukin; MMP, matrix metallopeptidase; NP, nucleus pulposus; TNF, tumor necrosis factor; SOD, superoxide dismutase; RT-qPCR, reverse transcription-quantitative polymerase chain reaction

Key words: cartilage oligomatrix protein, chondroadherin, etanercept, intact intervertebral disc tissue, interleukin-1 $\beta$, matrix metalloproteinases, primary cell culture the treatment group, the chondroadherin gene, an NP-specific marker, was not expressed after $24 \mathrm{~h}$. By contrast, the cartilage oligo matrix protein was expressed 24,48 and $72 \mathrm{~h}$ post-ETA treatment, while its expression was significantly lower than that in the control group. In addition, the expression of interleukin-1 $\beta$, as well as matrix metallopeptidase-7 and -19, was markedly decreased. Overall, the cell proliferation and gene expression in the ETA-treated cells were significantly different from those in the control group $(\mathrm{P}<0.05)$. These results suggest that the treatment duration and dosage of TNF inhibitors, which are used to suppress active inflammation, should be considered in the clinical setting. These biological agents may delay the healing of intervertebral disc tissue damage by slowing cell proliferation and altering gene expression via anabolic and catabolic pathways.

\section{Introduction}

Tumor necrosis factor (TNF) increases the release of pro-inflammatory cytokines, including collagenase, leading to bone and cartilage resorption, as well as prostaglandin-E2, granulocyte-macrophage colony-stimulating factor and interleukins (ILs), with IL- $\beta,-6$, and -8 causing the induction of chemotaxis. In addition, $\mathrm{TNF}-\alpha$ has a major role in numerous other processes, including the activation of endothelial cells through adhesion molecules; the stimulation of macrophages, T cells and B cells; and the activation of maturing dendritic cells by altering the cell surface structure (1).

Biological disease-modifying antirheumatic drugs (DMARDs) block specific pathways and signals of inflammation (2). As alternatives, anti-TNF drugs, including infliximab, adalimumab and etanercept (ETA), have gained popularity in recent years as a treatment for common diseases 
(e.g., rheumatoid arthritis, ankylosing spondylitis and psoriatic arthritis) encountered in rheumatology practice that are unresponsive to DMARDs (2).

In the last decade, much research has focused on the effects of ETA on spinal and cranial pathologies in the field of neurosurgery (3-7). For instance, the use of ETA has been extensively investigated in spinal epidural fibrosis in a post-laminectomy rodent model (3), in subarachnoid hemorrhage (4), in Alzheimer's disease (5) and in partial spinal cord injury (6) in live mammals. ETA functions as a soluble TNF receptor fusion protein (p75 + immunoglobulin $G$ ) that blocks TNF- $\alpha$ and is effective in distinct stages of inflammation in rheumatic diseases (7). Antibodies against anti-TNF drugs reduce the effectiveness of these drugs and increase the risk of serious side effects. The average half-life of ETA, a lymphotoxin-binding agent, is $102 \mathrm{~h}$, without any effects of lysing TNF-expressing cells. In controlled trials, the administration of ETA at higher doses did not cause any change in the dose-response profile, but increased dose-associated side effects (7). For this reason, a dose not exceeding $50 \mathrm{mg}$ per week is recommended for clinical applications of ETA (7).

Certain drugs may accumulate in the body tissues of patients, and numerous studies have reported on the cytotoxic effects of accumulating drugs in the body (8-10). In terms of ETA, studies suggested that it may cause cerebral tumefactive demyelinating lesions (11), mycotic intracranial aneurysms (12) and cerebral abscess development (13). However, to the best of our knowledge, no previous study has focused on the positive or negative effects of this pharmacological agent on intervertebral disc tissue. Therefore, the aim of the present study was to investigate the effects of ETA on primary nucleus pulposus (NP) and annulus fibrosus (AF) cell cultures at the cytological and molecular level.

To evaluate the effects of ETA on cells from intervertebral disks in the present study, the expression levels of chondroadherin (CHAD), an NP-specific marker $(9,14)$, were examined. Furthermore, the levels of the cartilage oligo matrix protein (COMP) (15), which is involved in intervertebral disc catabolic metabolism, were determined. In addition to these markers, the levels of matrix metallopeptidase (MMP)-7 and MMP-19 were examined using reverse transcription-quantitative polymerase chain reaction (RT-qPCR) (16-21). MMP-7 and MMP-19 have a role in remodeling of the intervertebral disc and the extracellular matrix structure, as well as in the catabolic pathways of these tissues. In addition, the gene expression levels of IL-1 $\beta$ (22-25), the major pro-inflammatory cytokine of the intervertebral disc, were examined.

\section{Materials and methods}

Materials. ETA (Enbrel ${ }^{\circledR}$; Pfizer, Inc., New York, NY, USA) at a dose of $50 \mathrm{mg}$ was used. A RT-qPCR PureLink ${ }^{\mathrm{TM}}$ RNA Mini kit (cat. no. 12183020), High-Capacity complementary (c)DNA Reverse Transcription kit (cat. no. 4368814), TaqMan ${ }^{\circledR}$ Gene Expression Assay (FAM; cat. no. 4331182), CHAD TaqMan ${ }^{\circledR}$ Gene Expression Assay (ID, Hs00154382_m1), COMP $\operatorname{TaqMan}^{\circledR}$ Gene Expression Assay (ID, Hs00164359_m1), MMP-7 TaqMan ${ }^{\circledR}$ Gene Expression Assay (ID, Hs01042796_ m1), MMP-19 TaqMan $^{\circledR}$ Gene Expression Assay (ID, Hs00418247_g1), IL-1 $\beta$ TaqMan ${ }^{\circledR}$ Gene Expression Assay (ID,
Hs01555410_m1), $\beta$-actin TaqMan ${ }^{\circledR}$ Gene Expression Assay (ID, Hs01060665_g1) and TaqMan Fast Advanced Master Mix (cat. no. 4444557) were all procured from Thermo Fisher Scientific Inc. (Waltham, MA, USA).

Criteria for the inclusion or exclusion of the tissues obtained from the patients. Exclusion criteria for tissue collection were any pathology affecting the nervous system (e.g., human immunodeficiency virus infection), a weak immune system due to ill health, hepatitis B, severe nerve impairment, seizures, any numbness or tingling sensations, multiple sclerosis or Guillain-Barré syndrome; as previously explained, adverse effects may become more evident in such patients $(26,27)$. Of the tissues obtained, those from six patients were excluded due to the following reasons: Diagnosis of diabetes and treatment with anti-diabetic drugs $(n=2)$; cardiac insufficiency $(n=1)$; use of drugs, such as DMARDs $(n=1)$; and use of anakinra $(n=1)$ or abatacept $(n=1)$ within the last 6 months.

Preparation of cell cultures from human primary intervertebral disc tissue. A total of six patients with a mean age of $35 \pm 3.37$ years who were admitted to the emergency department of Training and Research Hospital of Namik Kemal University (Tekirdag, Turkey) between December 2017 and April 2018 due to spinal trauma and had undergone imaging and neurological examinations were included. All of the patients were diagnosed with traumatic lumbar intervertebral disc herniation and associated spinal cord edema and spinal instability based on magnetic resonance imaging. The patients were operated in the prone position under general anesthesia. Following a midline skin incision, the paravertebral muscles were sub-periosteally scraped to reach the traumatized area. Spinal fusion was performed through a laminectomy, traumatic disc hernia excision and the application of a transpedicular screw-rod system in the area where the spinal cord compression was detected. Following resection of intact intervertebral disc tissue, the tissue was placed in sterile containers containing penicillin-streptomycin (5\%) and Dulbecco's modified Eagle's medium (DMEM; cat. no. D5523; Sigma-Aldrich; Merck KGaA, Darmstadt, Germany). The samples were then transferred to the laboratory at $4^{\circ} \mathrm{C}$. Subsequently, the cultures were prepared in accordance with the protocol for the preparation of standard primary cell cultures $(9,14,28-30)$. Confluent primary cell cultures were passaged. In the third passage, the cells were stained with trypan blue and counted under an inverted light microscope. The counted cells were plated at $1.4 \times 10^{4}$ cells per well in 96-well plates, 3.6x10 4 cells per well in 24-well plates and 3.9 $\times 10^{6}$ cells per dish in Petri dishes $(100 \mathrm{~mm})$ for the MTT viability assay, inverted light microscopy and acridine orange (AO)/propidium iodide (PI) assays, as well as histopathological evaluation, respectively. After overnight incubation, drugs were added to perform experiments on the cell cultures that became confluent and adhered to the cell culture plates or dishes.

ETA treatment of the cell cultures. Human primary intact AF/NP cell cultures that were left untreated with ETA served as a control group. The ETA stock solution (concentration, $50 \mathrm{mg} / \mathrm{ml}$ ) was prepared by adding DMEM. To determine the ETA dose to be applied to the samples in the experimental groups, dose-response curves were generated for the determination of a suitable ETA 
dose, which would not be toxic prior to commencement of the experiments. Solutions containing different concentrations of ETA $(0.1,0.25,0.5,1$ and $2 \mathrm{mg} / \mathrm{ml} ; 1 \mathrm{ml}$ volume) were prepared by adding DMEM to $50 \mathrm{mg} / \mathrm{ml}$ of ETA stock solution for use in the dose-response curve studies. The ETA solutions with concentrations of $0.1,0.25,0.5,1$ and $2 \mathrm{mg} / \mathrm{ml}$ were added to the respective cell cultures. To determine cell viability, the MTT assay was used as a preliminary experiment. The cell proliferation was completely inhibited at doses of $>0.5 \mathrm{mg} / \mathrm{ml}$. For this reason, $10 \mu \mathrm{l}$ ETA solution with a final concentration of $0.5 \mathrm{mg} / \mathrm{ml} /$ well, which still allowed for cell proliferation, was administered to the experimental group of $\mathrm{AF} / \mathrm{NP}$ cell cultures.

Inverted light/fluorescence microscopy, AO/PI and Giemsa staining. Cell surface morphologies were examined under magnifications of $\mathrm{x} 4, \mathrm{x} 10, \mathrm{x} 20$ and $\mathrm{x} 40$ using an inverted light microscope (model no. CKX41; Olympus, Tokyo, Japan). Photomicrographs of cell organization were obtained and analyzed during the confocal/contrast phase using Olympus Cell Soft Imaging System software (Cell A 5.1; Olympus). A fluorescent microscope (DM 2500; Leica Microsystems, Wetzlar, Germany) was used for analysis of AO/PI staining.

To determine cell viability and confirm the results of the MTT assay, nucleic acid binding dyes (AO and PI) were used. AO generates green fluorescence and stains all nucleated cells, irrespective of whether alive or dead. PI stains nucleated cells but is only able to enter dead cells with poor membrane integrity and generates red fluorescence. To prepare the AO/PI stain, $4 \mathrm{mg}$ AO (dissolved in $2 \mathrm{ml}$ of $99 \%$ ethanol), $10 \mathrm{~g}$ sodium-EDTA, $4 \mathrm{mg}$ PI and $50 \mathrm{ml}$ fetal bovine serum (cat. no. 10270; Gibco; Thermo Fisher Scientific, Inc. Waltham, MA, USA) were thoroughly mixed, and sterile distilled water was added to reach a final volume of $200 \mathrm{ml}(9,14,29,31)$. To stain the cultures, the cell culture medium was discarded, and AO/PI stain was added to cover the surface of the plates, followed by incubation for $10 \mathrm{~min}$ in the dark and subsequent monitoring using a fluorescent microscope.

No toxic effect from the ethanol was observed due to the short administration time and because AO/PI dye contains $<1 \%$ ethanol. A number of studies have previously reported that cell death observed following such ethyl alcohol administrations are not caused by ethanol, but are caused by the drug applied $(32,33)$. In addition, spontaneous apoptotic cell death has been demonstrated to occur even if no administration is performed in the culture medium. Therefore, $>100$ cells were counted through a microscope in the experimental groups and apoptotic cell death, if it was $>5 \%$, was reported to be due to the applied drug.

For Giemsa staining, the cells in the petri dishes were fixed with a glutaraldehyde (8\%) and cacodylate buffer (25\%) solution for histopathological evaluation and then stained with Giemsa. Images were captured under a light microscope at a magnification of $\times 20$.

Cell viability analyses using MTT assay. The MTT assay was performed using a commercial kit (Vybrant MTT Cell Proliferation Assay; cat. no. V-13154; Cell Biolabs, San Diego, CA, USA). In brief, $1 \mathrm{ml}$ MTT stock solution $(5 \mathrm{mg} / \mathrm{ml})$ was prepared with sterile PBS. After the abovementioned treatments, the cell culture medium was discarded and $100 \mu \mathrm{l}$ of this MTT stock solution was added to each well, followed by incubation for $4 \mathrm{~h}$ in a $5 \% \mathrm{CO}_{2}$ incubator. Subsequently, $50 \mu \mathrm{l}$ of the solution in each well was discarded and $25 \mu$ l dimethyl sulfoxide (Sigma-Aldrich; Merck KGaA, Darmstadt, Germany) was added to each well. Following incubation for $15 \mathrm{~min}$ in an incubator at a temperature of $37.4^{\circ} \mathrm{C}$ with $5 \% \mathrm{CO}_{2}$ to stop the reaction, analyses were performed at $570 \mathrm{~nm}$ wavelength with a spectral photometer (UV Mini 1240-UV-V15 Spectrophotometer; Shimadzu, Kyoto, Japan).

$R T$ - $q P C R$ analysis. RNA isolation from primary cultured cells was performed using the PureLink ${ }^{\mathrm{TM}}$ RNA Mini kit (cat. no. 12183018A; Thermo Fisher Scientific, Inc.). The amount of RNA obtained from all of the samples was determined spectrophotometrically. cDNA was then synthesized by RT of $100 \mathrm{ng}$ RNA. An Applied Biosystems High-Capacity cDNA Reverse Transcription kit (cat. no. 4368813) was used to perform RT. Changes in the expression of CHAD, COMP, MMP-7, MMP-19 and IL-1 $\beta$ genes were analyzed using RT-qPCR with TaqMan ${ }^{\circledR}$ Gene Expression Assay (FAM) kits in accordance with the manufacturer's protocol. $\beta$-actin was used as the internal control gene (housekeeping gene). The expression of each gene was normalized to that of $\beta$-actin in the same cell culture. Pre-test cultures without ETA application (group 1, $0 \mathrm{~h}$ ) were used as reference samples and their gene expression levels were quantified using the $2^{-\Delta \Delta C q}$ method and were set as 1 for relative quantification (RQ) of the expression of the analyte genes (34). At 24, 48 and $72 \mathrm{~h}$, the fold change in gene expression was calculated as the RQ.

Statistical analysis. Statistical analyses were performed using SPSS software (version 20.0; IBM Corp., Armonk, NY, USA). Continuous variables were presented as the mean \pm standard deviation. Analysis of variance was performed to assess whether there were significant differences among multiple groups, followed by Tukey's honestly significant difference post-hoc test for multiple pairwise comparisons. $\mathrm{P}<0.05$ was considered to indicate statistical significance.

\section{Results}

ETA decreases the proliferation and viability of AF/NP cells. Confluent primary cultures were trypsinized and detached cells were cultivated in experimentally appropriate culture dishes after centrifugation. After $24 \mathrm{~h}$ of incubation, the first-passage cultures were obtained and ETA administration was commenced. Representative microscopy images of the cells are provided in Fig. 1. A phase contrast microscopy image (magnification, x10) of the cultures at $0 \mathrm{~h}$ is presented in Fig. 1A. In these cultures, the cells were attached and began to proliferate, and no cell death resulting from passaging was observed (AO/PI staining; x10 magnification; Fig. 1B). The results of Giemsa staining (magnification, $\mathrm{x} 40$ ) at $0 \mathrm{~h}$ are displayed in Fig. 1C. As displayed in the subfigures, the cell viability in the control group continued to increase after 24, 48 and $72 \mathrm{~h}(\mathrm{P}<0.05)$. Phase contrast microscopy, AO/PI staining and Giemsa staining images of the control group cultures at $24 \mathrm{~h}$ are displayed in Fig. 1G-I, those at $48 \mathrm{~h}$ are displayed in Fig. 1M-O, and those at $72 \mathrm{~h}$ are displayed in Fig. 1S-U, respectively. Likewise, phase contrast microscopy, AO/PI staining and Giemsa staining images of the cultures treated with ETA for $24 \mathrm{~h}$ are displayed in Fig. 1D-F, those 

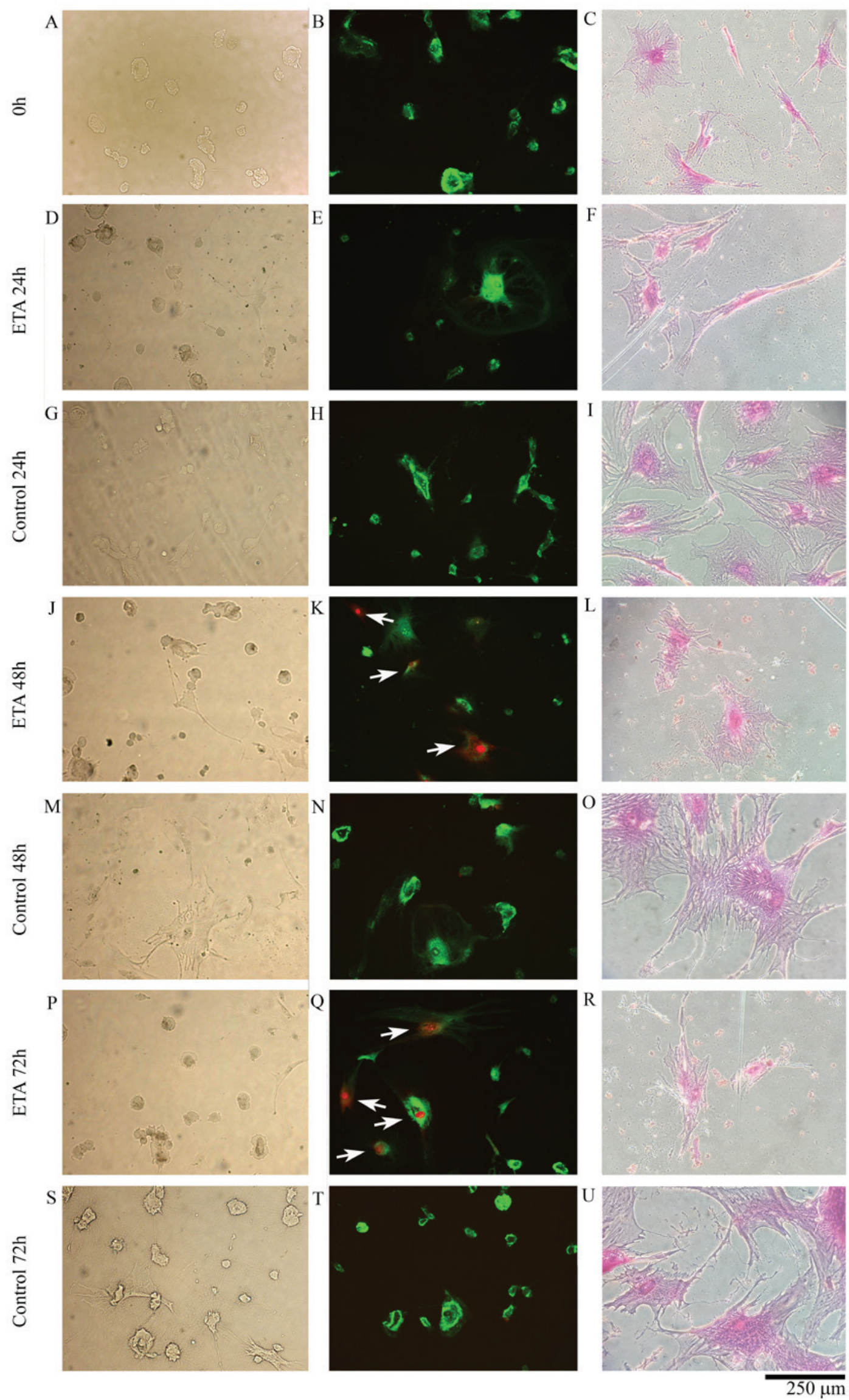

Figure 1. (A-U) Photomicrographs of samples obtained using inverted light or fluorescence microscopes. (A, D, G, J, M, P and S) The first column displays images for each experimental group recorded using an inverted light microscope. (B, E, H, K, N, Q and T) Acridine orange/propidium iodide staining results of the same cultures are provided in the second column. Apoptotic cells with a red nucleus (or whole body) and green cytoplasm are indicated with white arrows. (C, F, I, L, O, R and U) Giemsa staining of the same cultures, provided to better reflect the cell and extracellular matrix organization, is presented in the third column (scale bar, $250 \mu \mathrm{m}$ ). ETA, etanercept. 
Table I. Assessment of the cell viability of intact tissues following etanercept treatment.

\begin{tabular}{lcccc}
\hline Group & $0 \mathrm{~h}$ & $24 \mathrm{~h}$ & $48 \mathrm{~h}$ & $72 \mathrm{~h}$ \\
\hline Control & $0.271 \pm 0.03$ & $0.285 \pm 0.01$ & $0.315 \pm 0.01$ & $0.418 \pm 0.05$ \\
Etanercept-treated & $0.271 \pm 0.03$ & $0.279 \pm 0.05^{\mathrm{a}}$ & $0.308 \pm 0.02^{\mathrm{a}}$ & $0.307 \pm 0.01^{\mathrm{a}}$
\end{tabular}

${ }^{\text {a }}<0.05$ vs. the etanercept-treated group at $0 \mathrm{~h}$. The values provided are the optical densities of the cells.

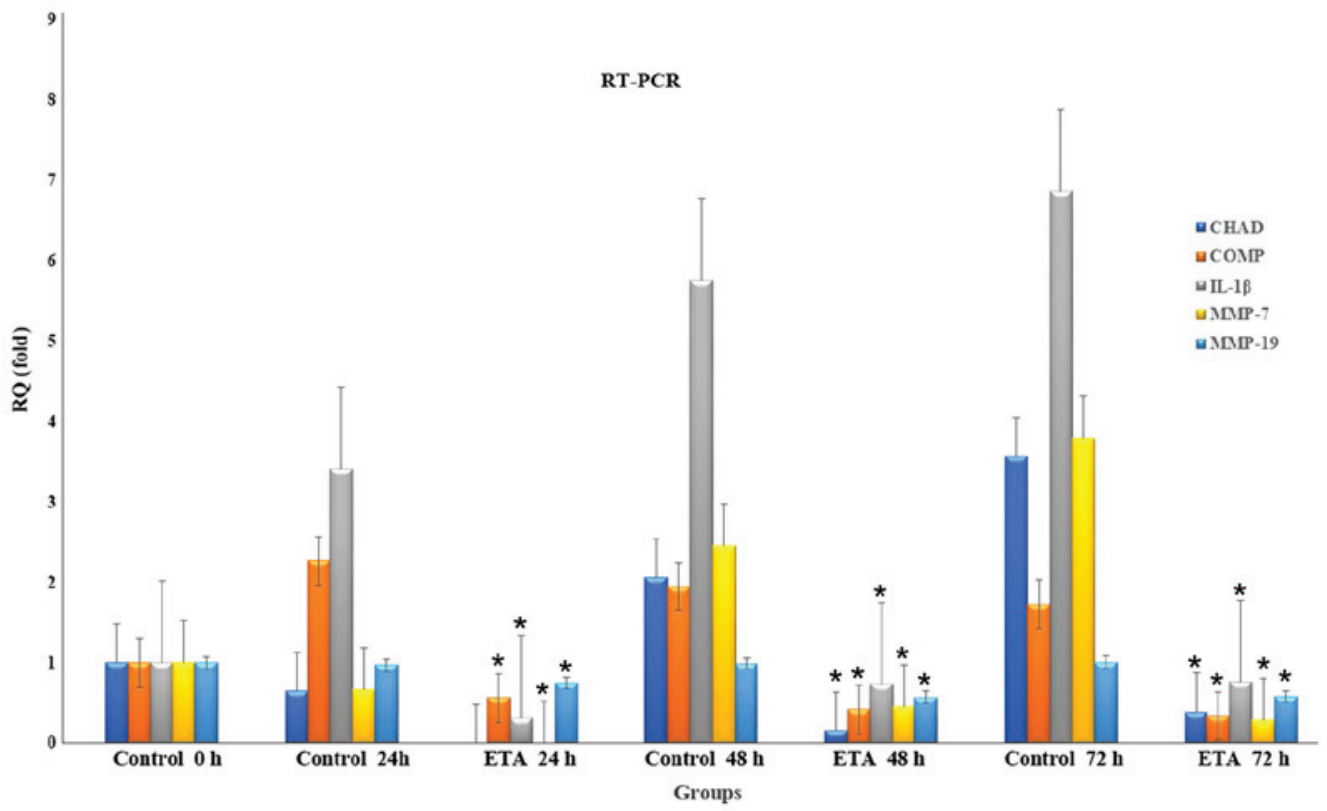

Figure 2. RQ values obtained using RT-qPCR analysis. Cultures were prepared from the tissues of intact intervertebral discs $(\mathrm{n}=6)$ resected from patients and treated with or without ETA. The expression of CHAD, COMP, IL-1 $\beta$, MMP-7 and MMP-19 was assessed at 0, 24, 48 and $72 \mathrm{~h}$. "P<0.05 vs. intact intervertebral disc tissue (control) at $0 \mathrm{~h}$. CHAD, chondroadherin; COMP, cartilage oligomatrix protein; IL, interleukin; MMP, matrix metallopeptidase; RQ, relative quantification; ETA, etanercept; RT-qPCR, reverse transcription-quantitative polymerase chain reaction.

treated with ETA for $48 \mathrm{~h}$ in Fig. 1J-L, and those treated with ETA for $72 \mathrm{~h}$ in in Fig. 1P-R, respectively. In the control group cultures, continuous cell proliferation was evident; cells maintained their specific morphology. Also, no apoptotic cell death was observed in these cultures. However, in the cultures treated with ETA, the cell viability was suppressed, and certain cells underwent apoptotic cell death $(\mathrm{P}<0.05)$. With the incubation time progressing, the amount of apoptotic cell death increased, as revealed by AO/PI staining (Fig. $1 \mathrm{~K}$ and Q, white arrows). Morphological analysis indicated that the ETA-treated cells exhibited a response typical for that to exposure to cytotoxic agents (i.e. a rounder shape and a tendency to become detached from the flask surface; Fig. 1D, J and P).

The results of the MTT assay confirmed the morphological observations (Table I). They revealed that the cell proliferation increased with time in the control group, whereas the proliferation was suppressed in the cultures treated with ETA $(\mathrm{P}<0.05$; Fig. 1 and Table I).

ETA decreases the expression of genes in AF/NP cells. The RQ values obtained for the experimental group are presented in Fig. 2. In the 24-h cultures of the control group, CHAD expression was lower than that of the reference sample $(R Q=0.65)$ but increased over time, with $\mathrm{RQ}=2.06$ and 3.57 after 48 and
$72 \mathrm{~h}$, respectively $(\mathrm{P}<0.05)$. In the ETA-treated cells, CHAD expression was absent after $24 \mathrm{~h}$ of incubation. After 48 and $72 \mathrm{~h}, \mathrm{CHAD}$ expression in the ETA-treated cells was $\sim 13-$ and $\sim 9$-fold lower, respectively, compared with that in the control group $(\mathrm{P}<0.05)$. Similar results were obtained for COMP, IL-1 $\beta$, MMP-7 and MMP-9 expression in the ETA-treated samples. COMP expression in the cultures was lower than that in the control group ( 4-, $\sim 4.6$ - and $\sim 5$-fold after 24,48 and $72 \mathrm{~h}$, respectively). In comparison, the decrease in IL-1 $\beta$ expression was greater, with the expression of this gene in the ETA-treated cultures being decreased by $\sim 10.6-, \sim 7.7-$ and $~ 9$-fold of that in the control group after 24,48 and $72 \mathrm{~h}$, respectively $(\mathrm{P}<0.05)$. In the ETA-treated cells, MMP-7 expression was absent in the 24-h cultures and at subsequent time-points, it was lower than that in the control group (5-fold after $48 \mathrm{~h}$ and 13-fold after 72 h). MMP-19 gene expression in the ETA-treated group was slightly lower than that in the control group, with expression fold changes of $\sim 1.3-, \sim 1.7-$ and $\sim 1.7$ after 24,48 and $72 \mathrm{~h}$ in the ETA-treated cultures $(\mathrm{P}<0.05)$.

\section{Discussion}

Improvements in the pharmaceutical technology and pharmaco-molecular fields have led to the use of biological agents 
that may influence, regulate and alter the biological response of the immune system as clinical treatment modalities. As for other biological DMARDs, efficiency and safety studies on ETA are ongoing. Wadhwa et al (31) tested the neutralization activity of preparations of ETA against the third TNF- $\alpha$ international standard in different in vitro cell-based assays (e.g., cytotoxicity, apoptosis and reporter gene methods) using the commercial cell line L929.

In in vitro systems, such as cell lines, there are no complex interactive mechanisms with the microenvironment of the cells. Furthermore, as the genetic structure of the cells in the cell line has been modified, they do not carry the genotypic and phenotypic characteristics that they have in the human body. Therefore, the results obtained using experimental setups with commercial cell lines may be misleading $(7,9,10,14,28,30)$.

A previous study on the effects of various biological agents on human chondrocytes and osteocytes in vitro reported side effects and adverse events, and even cytotoxicity (2). The study used primary cell cultures prepared from tissue obtained from patients with gonarthrosis and performed morphological and molecular-level analyses of these cell cultures prior to and after the application of various biological agents. The study reported that rituximab and adalimumab were toxic to chondrocytes, whereas adalimumab and ETA were toxic to osteocytes. However, to the best of our knowledge, the effects of ETA on $\mathrm{NP} / \mathrm{AF}$ cells have not been previously reported. Therefore, the data obtained in the present study may significantly contribute to the current knowledge in the field.

Most basic research suggests that anti-TNF- $\alpha$ therapy may be beneficial for sciatica treatment. For instance, Beyaz et al (35) indicated that inflammatory cytokines secreted from NP tissue led to symptoms similar to those observed in lumbar radiculopathy. They compared the effectiveness of TNF- $\alpha$ antagonists applied via intravenous or epidural routes in lumbar spinal pathologies and concluded that TNF- $\alpha$ antagonists administered epidurally may lead to accelerated healing of radiculopathy-associated allodynia.

Watanabe et al (36) reported that $\mathrm{TNF}-\alpha$, as an inflammatory cytokine, may cause neuropathic pain, including sciatica. Their study on adult male Sprague Dawley rats elucidated the effects of ETA in a dorsal root ganglion (DRG) compression model and reported that ETA treatment reduced pain-associated behaviors induced by DRG compression. They concluded that ETA, in addition to its effects on NP in lumbar disc herniation, may reduce the mechanical effects on the DRG.

Wang et al (37) investigated the expression of the ADAM metallopeptidases with thrombospondin type 1 motif-like 7 (ADAMTS-7) gene, which may have a potential role in disc degeneration on cell cultures prepared from NP tissues. The study suggested that the increase of ADAMTS-7 stimulated by IL-17A was significantly reduced in the group treated with ETA when compared with the control group. Furthermore, they indicated that IL-17A induced ADAMTS-7 expression through TNF- $\alpha$, which may resemble a molecular signaling axis in human NP cells.

Another study investigated the neuroprotective effects of ETA by examining histopathological and biochemical changes after spinal cord injury (SCI) in Wistar albino rats (1). The levels of TNF- $\alpha$, IL-1 $\beta$, superoxide dismutase (SOD), adenosine deaminase, catalase (CAT) and malondialdehyde were investigated in the tissue and serum. The results indicated that early application of ETA after SCI may significantly reduce neuronal damage by lowering tissue and serum TNF- $\alpha$ and IL- $1 \beta$ levels, while increasing the levels of anti-oxidative enzymes, including SOD and CAT, in sub-acute and acute stages.

Based on previous studies, Chen et al (38) hypothesized that deterioration of the structure of tendons stemmed from elevated expression of TNF- $\alpha$, and they studied the therapeutic potential of ETA in preventing morphological changes in the Achilles tendon in a rat model. In their study, the animals were exposed to stress shielding of the left Achilles tendon and then treated with ETA or PBS for 2 or 4 weeks. The right Achilles tendons with no ETA treatment served as a control group. At the end of the treatment period, the authors observed irregularities in collagen fibrils and a significant increase in the number of small-diameter collagen fibrils. They inferred that these changes may be associated with an increase in the expression of TNF- $\alpha$, MMP-3, MMP-13, collagen I and collagen III. They observed a decrease in morphological changes in collagen organization and structure induced by stress shielding at 2 weeks post-ETA treatment. The study suggested that the administration of ETA may have mitigated upregulation of MMP-13, MMP-3, and collagen III levels. However, there were no significant differences in the morphology of the Achilles tendons between the ETA-treated group and PBS group after 4 weeks of treatment (38).

Of note, the sensitivity of certain tissues may differ between humans and animals. Thus, the results obtained from studies based on animal models may differ from those obtained in human studies, and such results may be misleading $(7,9,10,14,28,30)$. Therefore, in the present study, no animal tissues or commercial cell lines were used. Instead, human primary cell cultures were prepared from intact human intervertebral disc tissue, which may enhance the value of the present study.

Crnkic et al (39) investigated the effect of the administration of infliximab and ETA on the COMP levels of patients with rheumatoid arthritis. They measured serum COMP levels at treatment initiation and at 3 and 6 months of treatment. They reported that the two TNF- $\alpha$ inhibitors had a protective effect in patients with rheumatoid arthritis. In addition, they indicated that serum COMP levels may be a useful marker for evaluating tissue-level effects of novel treatment modalities in patients with rheumatoid arthritis.

The results of the present study revealed that ETA administration suppressed the proliferation of AF/NP cells and caused an increase in cell death. In addition, ETA administration prevented the cells from forming a healthy microenvironment. In the cultured cells, the expression of the CHAD and COMP genes associated with extracellular matrix formation were significantly reduced. Numerous studies have reported that inflammation has a role in intravertebral disc degeneration, and certain studies suggested that the products resulting from extracellular matrix degradation may cause inflammation $(40,41)$. IL-1 $\beta$ is secreted from degenerate intervertebral disc cells. In the present study, the expression of the IL-1 $\beta$ gene was assessed to determine whether degeneration and extracellular matrix degradation occurred in the cultured intact AF/NP cells. IL-1 $\beta$ gene expression decreased significantly in the experimental group. Thus, IL-1 $\beta$ gene expression may be considered a marker of the protection of the cells' intact form $(42,43)$. COMP enables extracellular matrix elements and cells to bind extracellular 
matrix, and MMP-7 and MMP-19 are involved in the degradation of COMP $(15,16-21)$. As indicated by the results of the gene expression analysis in the present study, the expression of genes encoding these proteolytic enzymes was reduced in the ETA-treated group.

In the present in vitro study, ETA administration was observed to suppress IL-1 $\beta$ expression, a pro-inflammatory cytokine. It may be inferred from this finding that ETA administration clinically prevents inflammation development or suppresses inflammation in patients. In addition, the decrease in MMP-19 and MMP-7 expression levels may reduce the degradation of COMP in theory and enable cultured cells to secrete more ECM. However, COMP and CHAD expression levels were significantly decreased in ETA-treated cultures. It may be inferred from this finding that ETA administration suppresses more gene expression leves in cell cultures. The observation of ETA-induced cell death, deterioration of cell morphologies and slowing of proliferation in cell cultures supported this inference.

The present research was performed using an in vitro experimental setup with primary cell cultures that were established using tissues of six patients. However, it should be noted that these biological agents may delay the healing of intervertebral disc tissue damage by slowing cell proliferation and altering gene expression via anabolic and catabolic pathways. Of note, the present study has a number of limitations. All of the cell cultures were obtained from only six patients and were analyzed in vitro in experimental media. Molecular analyses should be performed using the same markers with tissues from a larger number of patients of different ethnicities.

In conclusion, ETA, a TNF- $\alpha$ inhibitor, which was indicated to have a low side-effect profile in clinical trials, is a biological agent that is frequently used to suppress inflammation in numerous diseases. In the present study, the expression of a number of genes was markedly reduced in ETA-treated primary cell cultures derived from intervertebral disc tissue. Although the level of apoptosis in the ETA-treated group was not significant as compared with that in the control group, ETA-induced suppression of AF/NP cell proliferation warrants consideration. The data obtained in the present study should be confirmed in primary cell cultures isolated from tissues derived from a larger case group. ETA has a number of indications in the clinical setting. Although the present study was performed in an in vitro laboratory setting, the results point to the necessity to consider the inhibitory effects of ETA on intervertebral disc tissue cells when prescribing this pharmaceutical agent in the clinic.

\section{Acknowledgements}

Not applicable.

\section{Funding}

No funding was received.

\section{Availability of data and materials}

The datasets used and/or analyzed during the current study are available from the corresponding author on reasonable request.

\section{Authors' contributions}

TC contributed to the study concept and design, preparation of manuscript, the acquisition of subjects and data, analysis and interpretation of data, and evaluation of reverse transcription-quantitative polymerase chain reaction and ELISA analyses. DYS contributed to the analysis and interpretation of the data, and preparation of human primary cell culture; DYS also performed and evaluated the reverse transcription-quantitative polymerase chain reaction analyses. $\mathrm{NuK}$ selected the patients who met the inclusion criteria and contributed to the statistical evaluation of results. IY contributed to the preparation of human primary cell culture and inverted light microscopy; IY and NuK also performed and evaluated the ELISA analyses, and prepared and stored etanercept (ETA). HO contributed to the preparation and storage of ETA, and statistical evaluation of the results. YA, ATS and YEK contributed to the analysis and interpretation of the data. TC, NuK, NeK, YEK, ATS, YA and OA diagnosed the patients, performed surgery on the patients, and contributed to the removal of tissues and the transfer of the tissues to the laboratory. TC, DYS, IY, NuK, YEK, AYG and OA contributed to the preparation and critical revision of the manuscript for important intellectual content. All authors have read and approved the final version of the manuscript.

\section{Ethics approval and consent to participate}

Approval regarding use of the human tissues for the establishment of the primary cell cultures was obtained from the local ethics committee in Istanbul Medipol University School of Medicine (no. 29.11.2017-10840098/604.01.01/E.44192.) Written informed consent was obtained from all of the patients undergoing surgery whose tissues were used for the preparation of the primary cell cultures.

\section{Patient consent for publication}

Not applicable.

\section{Competing interests}

The authors declare that they have no competing interests.

\section{References}

1. Hasturk AE, Baran C, Yilmaz ER, Arikan M, Togral G, Hayirli N Erguder BI and Evirgen O: Etanercept prevents histopathological damage after spinal cord injury in rats. Asian J Neurosurg 13: 37-45, 2018.

2. Isyar M, Bilir B, Yilmaz I, Cakmak S, Sirin DY, Guzelant AY and Mahirogullari M: Are biological agents toxic to human chondrocytes and osteocytes? J Orthop Surg Res 10: 118, 2015.

3. Turkoglu E, Tuncer C, Dinc C, Serbes G, Oktay M and Sekerci Z: Turk Neurosurg 24: 506-511, 2014.

4. Zhang BF, Song JN, Ma XD, Zhao YL, Liu ZW, Li Y, Sun P, Li DD, Pang HG and Huang TQ: Etanercept alleviates early brain injury following experimental subarachnoid hemorrhage and the possible role of tumor necrosis factor- $\alpha$ and c-Jun N-terminal kinase pathway. Neurochem Res 40: 591-599, 2015.

5. Roerink ME, Groen RJ, Franssen G, Lemmers-van de Weem B, Boerman OC and van der Meer JW: Central delivery of iodine-125-labeled cetuximab, etanercept and anakinra after perispinal injection in rats: Possible implications for treating Alzheimer's disease. Alzheimers Res Ther 7: 70, 2015. 
6. Bayrakli F, Balaban H, Ozum U, Duger C, Topaktas S and Kars HZ: Etanercept treatment enhances clinical and neuroelectrophysiological recovery in partial spinal cord injury. Eur Spine J 21: 2588-2593, 2012

7. Guzelant AY, Isyar M, Yilmaz I, Sirin DY, Cakmak S and Mahirogullari M: Are chondrocytes damaged when rheumatologic inflammation is suppressed? Drug Chem Toxicol 40: 13-23, 2017.

8. Sirin DY and Karaarslan N: Evaluation of the effects of pregabalin on chondrocyte proliferation and CHAD, HIF- $1 \alpha$ and COL2A1 gene expression. Arch Med Sci 14: 1340-1347, 2018.

9. Karaarslan N, Yilmaz I, Sirin DY, Ozbek H, Kaplan N, Kaya YE, Akyuva Y, Gurbuz MS, Oznam K and Ates O: Pregabalin treatment for neuropathic pain may damage intervertebral disc tissue. Exp Ther Med 16: 1259-1265, 2018.

10. Karaarslan N, Batmaz AG, Yilmaz I, Ozbek H, Caliskan T, Sirin D, Kaplan N, Oznam K and Ates O: Effect of naproxen on proliferation and differentiation of primary cell cultures isolated from human cartilage tissue. Exp Ther Med 16: 1647-1654, 2018.

11. Cereda CW, Zecca C, Mazzucchelli L, Valci L, Staedler C, Bassetti CL and Gobbi C: Tumefactive demyelinating lesions during etanercept treatment requiring decompressive hemicraniectomy. Mult Scler 19: 820-823, 2013.

12. Bowers CA, Saad D, Clegg DO, Ng P, Clayton F, Haydoura S and Schmidt RH: Rapidly fatal internal carotid artery mycotic aneurysm rupture in a rheumatoid patient taking a TNF- $\alpha$ inhibitor: Case report and literature review. J Neurol Surg A Cent Eur Neurosurg 76: 249-254, 2015.

13. Kasirye Y,Epperla N, Manne JR, Bapani S and Garcia-Montilla RJ Brain abscesses complicating acute pneumococcal meningitis during etanercept therapy. Clin Med Res 10: 230-235, 2012.

14. Karaarslan N, Yilmaz I, Ozbek H, Sirin DY, Kaplan N, Akyuva Y, Gonultas A and Ates O: Are specific gene expressions of extracellular matrix and nucleus pulposus affected by primary cell cultures prepared from intact or degenerative intervertebral disc tissues? Turk Neurosurg 29: 43-52, 2019.

15. Chen S, Hu ZJ, Zhou ZJ, Lin XF, Zhao FD, Ma JJ, Zhang JF, Wang JY, Qin A and Fan SW: Evaluation of 12 novel molecular markers for degenerated nucleus pulposus in a Chinese population. Spine (Phila Pa 1976) 40: 1252-1260, 2015.

16. Goupille P, Jayson MI, Valat JP and Freemont AJ: Matrix metalloproteinases: The clue to intervertebral disc degeneration? Spine (Phila Pa 1976) 23: 1612-1626, 1998.

17. Kang JD, Stefanovic-Racic M, McIntyre LA, Georgescu HI and Evans $\mathrm{CH}$ : Toward a biochemical understanding of human intervertebral disc degeneration and herniation. Contributions of nitric oxide, interleukins, prostaglandin E2 and matrix metalloproteinases. Spine (Phila Pa 1976) 22: 1065-1073, 1997.

18. Kang JD, Georgescu HI, McIntyre-Larkin L, Stefanovic-Racic M, Donaldson WF III and Evans $\mathrm{CH}$ : Herniated lumbar intervertebral discs spontaneously produce matrix metalloproteinases, nitric oxide, interleukin-6 and prostaglandin E2. Spine (Phila Pa 1976) 21: 271-277, 1996.

19. Crean JK, Roberts S, Jaffray DC, Eisenstein SM and Duance VC: Matrix metalloproteinases in the human intervertebral disc: Role in disc degeneration and scoliosis. Spine (Phila Pa 1976) 22 2877-2884, 1997.

20. Doita M, Kanatani T, Ozaki T, Matsui N, Kurosaka M and Yoshiya S: Influence of macrophage infiltration of herniated disc tissue on the production of matrix metalloproteinases leading to disc resorption. Spine (Phila Pa 1976) 26: 1522-1527, 2001.

21. Matsui Y, Maeda M, Nakagami W and Iwata $H$ : The involvement of matrix metalloproteinases and inflammation in lumbar disc herniation. Spine 23: 863-869, 1998.

22. Nishida Y, D'Souza AL, Thonar EJ and Knudson W: Stimulation of hyaluronan metabolism by interleukin-1alpha in human articular cartilage. Arthritis Rheum 43: 1315-1326, 2000.

23. van den Berg WB: The role of cytokines and growth factors in cartilage destruction in osteoarthritis and rheumatoid arthritis. Z Rheumatol 58: 136-141, 1999.

24. Takae R, Matsunaga S, Origuchi N, Yamamoto T, Morimoto N, Suzuki S and Sakou T: Immunolocalization of bone morphogenetic protein and its receptors in degeneration of intervertebral disc. Spine (Phila Pa 1976) 24: 1397-1401, 1999.

25. Rannou F, Corvol MT, Hudry C, Anract P, Dumontier MF, Tsagris L, Revel M and Poiraudeau S: Sensitivity of anulus fibrosus cells to interleukin 1 beta. Comparison with articular chondrocytes. Spine (Phila Pa 1976) 25: 17-23, 2000.
26. Shin IS, Baer AN, Kwon HJ, Papadopoulos EJ and Siegel JN: Guillain-Barré and Miller Fisher syndromes occurring with tumor necrosis factor alpha antagonist therapy. Arthritis Rheum 54: 1429-1434, 2006

27. Highlights of Prescribing Information. In: Medication Guide. https://www.pi.amgen.com/ /media/amgen/repositorysites/pi-amgencom/enbrel/enbrel_pi.pdf. Accessed March 6, 2019.

28. Akyuva Y, Kaplan N, Yilmaz I, Ozbek H, Sirin DY, Karaarslan N, Guler O and Ates O: Delivering growth factors through a polymeric scaffold to cell cultures containing both nucleus pulposus and annulus fibrosus. Turk Neurosurg 29: 180-193, 2019.

29. Karaarslan N, Yilmaz I, Akgun FS, Caliskan T, Simsek AT, Kaplan N, Kaya YE, Sirin DY, Ozbek H and Ates O: Which pharmacological agents may be used to establish healthy, proliferating human primer nucleus pulposus/annulus fibrosus cell cultures? Systematic evaluation of our experience in the light of literature. Merit Res J Med Med Sci 6: 100-110, 2018.

30. Akyuva Y, Karaarslan N, Yilmaz I, Ozbek H, Sirin DY, Gurbuz MS, Kaya YE, Kaplan N and Ates O: How scaffolds, which are polymeric drug delivery systems allowing controlled release, can be tested in human primary nucleus pulposus and annulus fibrosus cell cultures? Merit Res J Med Med Sci 5: 477-487, 2017.

31. Wadhwa M, Bird C, Dilger P, Rigsby P, Jia H and Gross MEB; participants of the study: Establishment of the first WHO international standard for etanercept, a TNF receptor II Fc fusion protein: Report of an international collaborative study. J Immunol Methods 447: 14-22, 2017.

32. Jamalzadeh L, Ghafoori H, Sariri R, Rabuti H, Nasirzade J, Hasani $\mathrm{H}$ and Aghamaali MR: Cytotoxic effects of some common organic solvents on MCF-7, RAW-264.7 and human umbilical vein endothelial cells. Avicenna J Med Biochem 4: e33453, 2016.

33. Dolganiuc A and Szabo G: In vitro and in vivo models of acute alcohol exposure. World J Gastroenterol 15: 1168-1177, 2009.

34. Livak KJ and Schmittgen TD: Analysis of relative gene expression data using real-time quantitative PCR and the 2(-Delta Delta C(T)) method. Methods 25: 402-408, 2001.

35. Beyaz SG, İnanmaz ME, Ergönenç T, Palabiyik O, Tomak Y and Tuna AT: Comparison of the intravenous and epidural administration of tumor necrosis factor-alpha antagonists in an experimental rat pain model. Anesth Essays Res 11: 898-901, 2017.

36. Watanabe K, Yabuki S, Sekiguchi M, Kikuchi S and Konno S: Etanercept attenuates pain-related behavior following compression of the dorsal root ganglion in the rat. Eur Spine J 20: 1877-1884, 2011.

37. Wang SS, Zhang W, Zhang YQ, Zhao Y, Liu Y, Li JK, Zhang HX, Cheng L and Nie L: IL-17A enhances ADAMTS-7 expression through regulation of TNF- $\alpha$ in human nucleus pulposus cells. J Mol Histol 46: 475-483, 2015.

38. Chen K, Li P, Zhao H, Yan X and Ma Y: Effects of tumor necrosis factor inhibitor on stress-shielded tendons. Orthopedics 40: 49-55, 2017.

39. Crnkic M, Månsson B, Larsson L, Geborek P, Heinegård D and Saxne T: Serum cartilage oligomeric matrix protein (COMP) decreases in rheumatoid arthritis patients treated with infliximab or Etanercept. Arthritis Res Ther 5: R181-R185, 2003.

40. Molinos M, Almeiada CR, Calderia J, Cunha C, Gonçalves RM and Barbosa A: Inflammation in intervertebral disc degeneration and regeneration. J R Soc Interface 12: 20141191, 2015.

41. Khan AN, Jacobsen HE, Khan J, Filippi CG, Levine M, Lehman RA Jr, Riew KD, Lenke LG and Chahine NO: Inflammatory biomarkers of low back pain and disc degeneration: a review. Ann N Y Acad Sci 1410: 68-84, 2017.

42. Wang S, Liu C, Sun Z, Yan P, Liang H, Huang K, Li C and Tian J: IL-1 $\beta$ increases asporin expression via the $N F-\kappa B$ p 65 pathway in nucleus pulposus cells during intervertebral disc degeneration. Sci Rep 7: 4112, 2017.

43. Erwin WM, Islam D, Inman RD, Fehlings MG and Tsui FW: Notochordal cells protect nucleus pulposus cells from degradation and apoptosis: Implications for the mechanisms of intervertebral disc degeneration. Arthritis Res Ther 13: R215, 2011.

This work is licensed under a Creative Commons Attribution-NonCommercial-NoDerivatives 4.0 International (CC BY-NC-ND 4.0) License. 